\title{
Fabrication of New Geopolymer Binder from Demolition Waste and Ignimbrite Slits for Application in the Construction Industry
}

\author{
D.L. Mayta-Ponce ${ }^{a}$, P. Soto-Cruz and F.A. Huamán-Mamani \\ Grupo de Investigación en Ciencia y Tecnología de Materiales-CITEM, Universidad Católica San Pablo, Arequipa, Perú.
}

\begin{abstract}
Geopolymeric mortars with volumetric fractions of 0.6:1:0.3 for a binder powder, fine sand and sodium hydroxide solution $(12 \mathrm{M})$, respectively; have been fabricated by mixing the solid materials and the subsequent addition of sodium hydroxide solution $12 \mathrm{M}$ to form a workable paste, to later be cured for 28 days at room temperature. The microstructures of the fabricated materials reveal the existence of two phases with notable difference, one continuous to the geopolymer binder phase and another discontinuous of fine sand particles agglutinated by the binder phase. Mechanical compression tests are performed at a constant compression rate of 0.05 $\mathrm{mm} / \mathrm{min}$ and at temperatures ranged from room temperature to $500^{\circ} \mathrm{C}$. The mechanical results are ranged from 19 and $69 \mathrm{MPa}$ for all the materials studied. On the other hand, there was an increase in mechanical resistance up to test temperatures of $200^{\circ} \mathrm{C}$ and the progressive reduction of resistance at temperatures above $200^{\circ} \mathrm{C}$, with a fragile-ductile transition zone between 400 and $500^{\circ} \mathrm{C}$ and completely ductile behavior from test temperatures of $500^{\circ} \mathrm{C}$.
\end{abstract}

\section{Introduction}

In recent years, construction in Peru has had significant growth, which has generated a greater demand for construction materials. Traditional building materials such as Portland cement (PC) and clay bricks need a large amount of raw material to be fabricated. The PC, for example, plays a leading role in construction, because it is the main ingredient of mortars and concrete, however, the production of PC requires large amounts of raw material and generates a significant amount of $\mathrm{CO} 2$. It has been reported that $1.5 \mathrm{~T}$ of raw material is required to produce $1 \mathrm{~T}$ of $\mathrm{PC}$ and $0.9 \mathrm{~T}$ of $\mathrm{CO} 2$ is released into the atmosphere [1,2]. The knowledge of the harmful effects of global warming on our planet and a greater environmental awareness has allowed us to promote the search for alternative environmentally friendly construction materials [3], and geopolymeric materials are a very promising eco-friendly alternative [4].

Repairs and/or infrastructure improvements generate a huge amount of concrete waste, mortar and clay bricks (construction and demolition waste - C\&D), in addition to the difficulty of finding a suitable place for the disposal of C\&D. There are several works based on the recycling of $C \& D$, but most of them focus on its use as an aggregate of new mortars and concrete for nonstructural applications [5-7]. The difference between using recycled $C \& D$ aggregate and natural aggregate is that the first one has greater water absorption, abrasion loss and crushing capacity, but lower bulk density, the use of $C \& D$ recycled aggregate in the fabrication of new concrete and mortars generally leads to materials with lower resistance and durability, therefore, the use of recycled aggregate is quite limited. Other researchers have tried to re-clinker the cement coming from the C\&Ds to obtain a new cement, this process includes stages of separation of the cement and the aggregates, and re-clinkering that consumes a large amount of energy and, therefore, generated large amounts greenhouse gases $[8,9]$

On the other hand, the city of Arequipa is known as the white city, because its heritage buildings were made using a rock known as "SILLAR" (ignimbrite). The ignimbrite is an igneous rock produced by the sudden cooling of magma, composed mainly of rhyolite, andesite and dacite, currently it is used as a construction material because it can be easily extracted from quarries [10]. However, the uncontrolled exploitation of this material has generated the accumulation of large amounts of dust and slits in the quarries, limiting the consolidation of important tourism projects.

\section{Experimental procedure}

Geopolymeric mortars were prepared from four types of raw materials: ignimbrite, demolition mortar, calcined clay and commercial fine sand. The ignimbrite was collected from the area called "Quebrada de Añashuayco" (Arequipa-Peru), while the demolition mortar and calcined clay were obtained from a demolition zone near the city of Arequipa. The four types of raw materials were ground and sieved by ASTM No. 140 mesh (mesh size of 106 microns). In parallel, a solution of sodium hydroxide with 12 molar concentration was prepared.

\footnotetext{
a Corresponding author: dlmayta@ucsp.edu.pe
} 
The actual density, particle size distribution, crystalline phases and microstructures of the raw materials were determined by helium pycnometry, laser diffraction granulometry, X-ray diffraction and scanning electron microscopy, respectively, performed at the Centro de Investigación, Tecnología e Innovación of the Universidad de Sevilla - CITIUS (Spain).

For the preparation of geopolymeric mortars, volumetric fractions in $0.6: 1: 0.3$ ratio of raw material (ignimbrite, demolition mortar or calcined clay), fine sand and $12 \mathrm{M}$ sodium hydroxide solution were measured separately. The powder materials (binder powder and fine sand) were dry mixed for 10 minutes and then the sodium hydroxide solution was added and mixed for an additional 10 minutes. Workable pastes were obtained which were pressed uniaxially for 5 minutes in a cylindrical mold of $20 \mathrm{~mm}$ diameter and then were dried, first, hermetically for 48 hours and then at room temperature for 28 days.

Prismatic samples of $5 \times 5 \times 10 \mathrm{~mm}$ were cut from dry geopolymeric cylinders for mechanical testing. Uniaxial compression tests were carried out at different temperatures, from room temperature to $500^{\circ} \mathrm{C}$ in air and at a constant compression rate of $0.05 \mathrm{~mm} / \mathrm{min}$, corresponding to an initial deformation rate of $8 \times 10-5$. The data obtained of strength and position were analyzed in stress vs. strain curves.

\section{Results and discussion}

Table 1 shows the real density data obtained for the four types of raw materials, which were used to calculate the mass fractions of the mixtures prepared in this research.

Table 1. Determination of the real density of the starting materials.

\begin{tabular}{lccc}
\hline Raw material & $\begin{array}{c}\text { Mass } \\
(\mathrm{g} .)\end{array}$ & $\begin{array}{c}\text { Volume } \\
(\mathrm{cm} 3)\end{array}$ & $\begin{array}{c}\text { Average real } \\
\text { density }(\mathrm{g} . / \mathrm{cm} 3)\end{array}$ \\
\hline Ignimbrite & 5.0702 & 2.0466 & 2.4774 \\
Calcined clay & 6.2478 & 2.3502 & 2.6584 \\
Demolition mortar & 6.3599 & 2.4802 & 2.5643 \\
Fine sand & 7.1178 & 2.6394 & 2.6967 \\
\hline
\end{tabular}

Figure 1 shows the distribution of particle sizes for the four types of starting materials, where the average particle size values for the ignimbrite, calcined clay, demolition mortar and fine sand are: 61, 68, 64 and 83 microns, respectively.

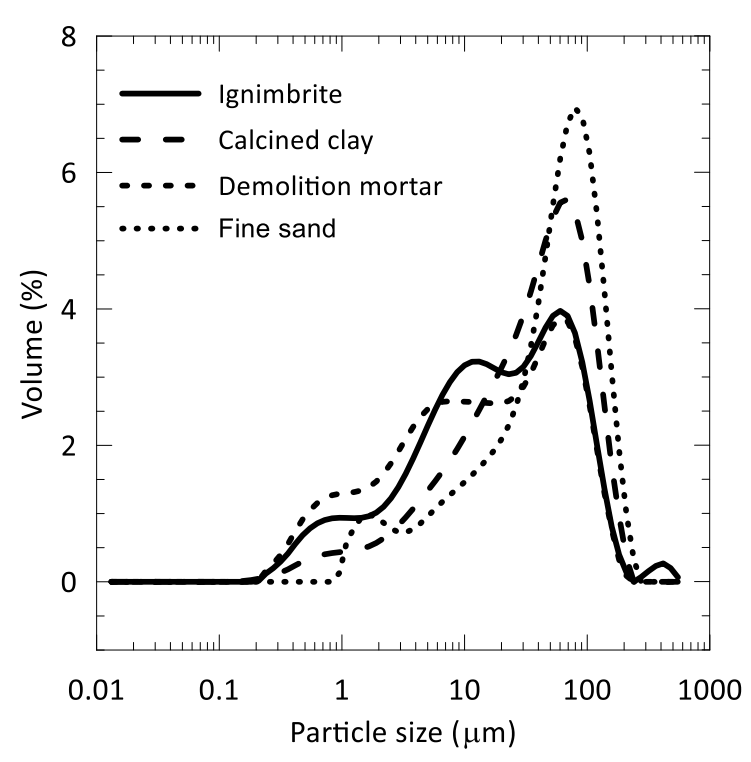

Figure1. Particle size distribution for raw material powders.

On the other hand, Figure 2 shows the typical microstructure of fabricated geopolymeric mortars, which consists of a continuous phase of geopolymeric binder in dark contrast and a discontinuous phase of fine sand particles in gray contrast.

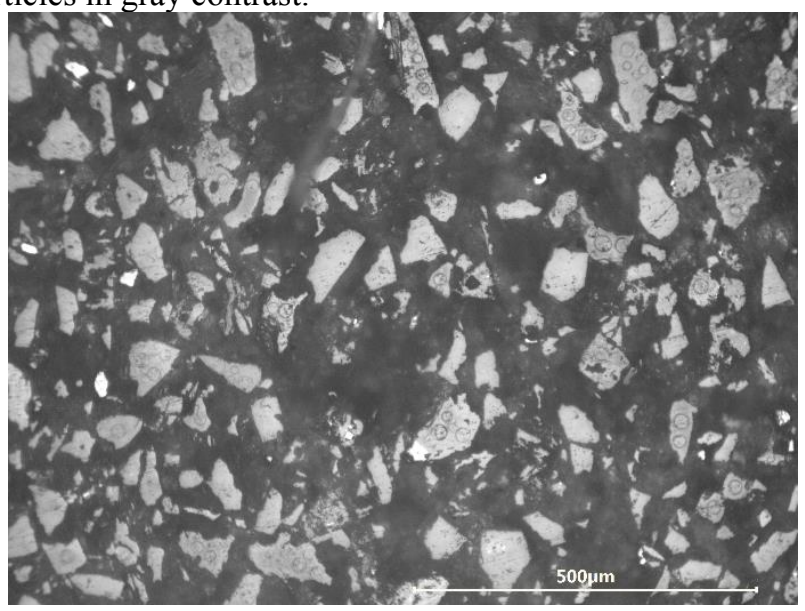

Figure2. Typical micrograph of a geopolymeric mortar sample obtained from ignimbrite powder.

From the X-ray diffraction spectra, the presence of various crystalline powder phases of the raw materials could be identified.

- Ignimbrite: Albite (NaAlSi3O8), Muscovite $(\mathrm{KAl} 3 \mathrm{Si3O} 10(\mathrm{OH}) 2)$, Cristobalite $(\mathrm{SiO} 2)$ and Microcline (KAlSi3O8).

- Demolition mortar: Quartz (SiO2), Albite (NaAlSi3O8), Muscovite (KAl3Si3O10(OH)2), Cristobalite (SiO2), Actinolite (Ca2(Mg,Fe2+)5Si8O22(OH)2), Anorthite (CaAl2Si2O8), Portlandite $(\mathrm{Ca}(\mathrm{OH}) 2)$, Calcite $(\mathrm{Ca}(\mathrm{CO}) 3) \quad \mathrm{y} \quad$ Chlorite ((Mg,Al)6(Si,Al)4O10(OH)8).

- Calcined clay: Quartz (SiO2), Albite (NaAlSi3O8), Muscovite (KAl3Si3O10(OH)2), Cristobalite (SiO2), Actinolite 
$(\mathrm{Ca} 2(\mathrm{Mg}, \mathrm{Fe} 2+) 5 \mathrm{Si} 8 \mathrm{O} 22(\mathrm{OH}) 2) \quad$ y Anatase (TiO2).

- Fine sand: Albite (NaAlSi3O8), Muscovite (KAl3Si3O10 $(\mathrm{OH}) 2)$ Cristobalite (SiO2), Actinolite $(\mathrm{Ca} 2(\mathrm{Mg}, \mathrm{Fe} 2+) 5 \mathrm{Si} 8 \mathrm{O} 22(\mathrm{OH}) 2) \quad \mathrm{y}$ Anorthite (CaAl2Si2O8).

Figures 3 to 5 show stress vs. strain curves at room temperature for the three types of geopolymeric mortars studied. The maximum and minimum stress values are in the range of 19 to $69 \mathrm{MPa}$.

These preliminary results show the potential for industrial application of these new construction materials, at least according of Peruvian regulations.

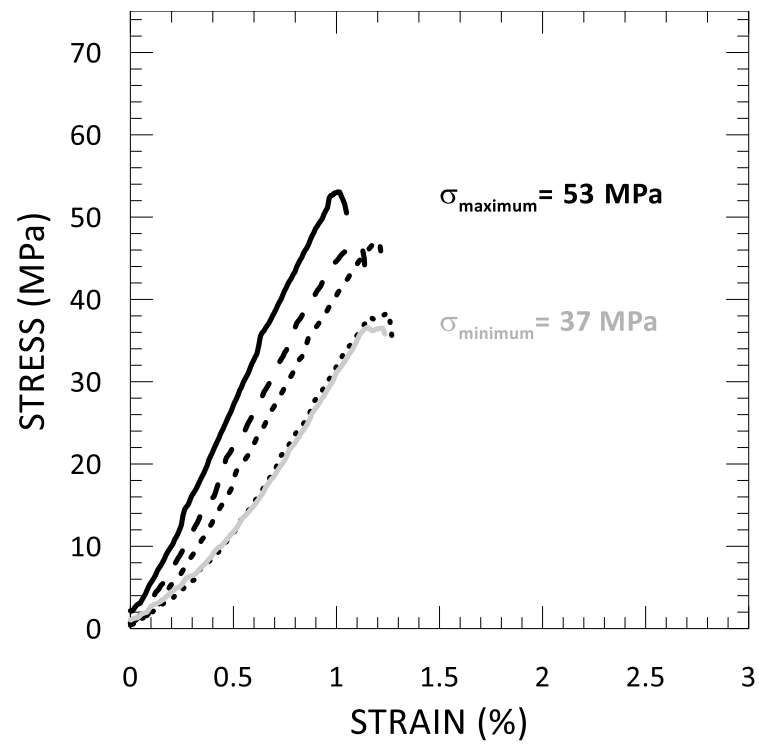

Figure 3. Stress vs strain curves for geopolymeric mortar derived from ignimbrite powder and deformed in air at room temperature.

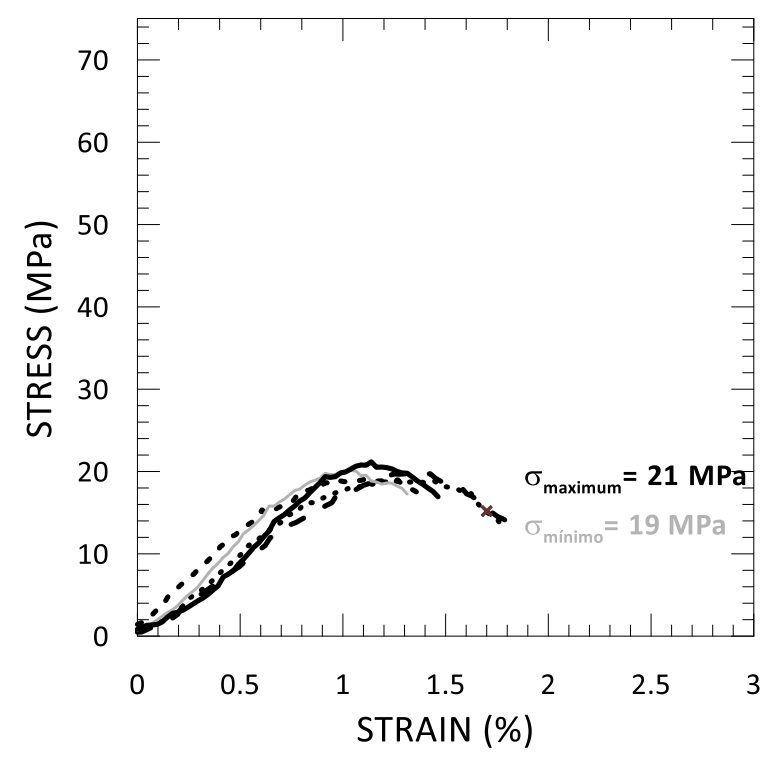

Figure 4. Stress vs strain curves for geopolymeric mortar derived from demolition mortar and deformed in air at room temperature.

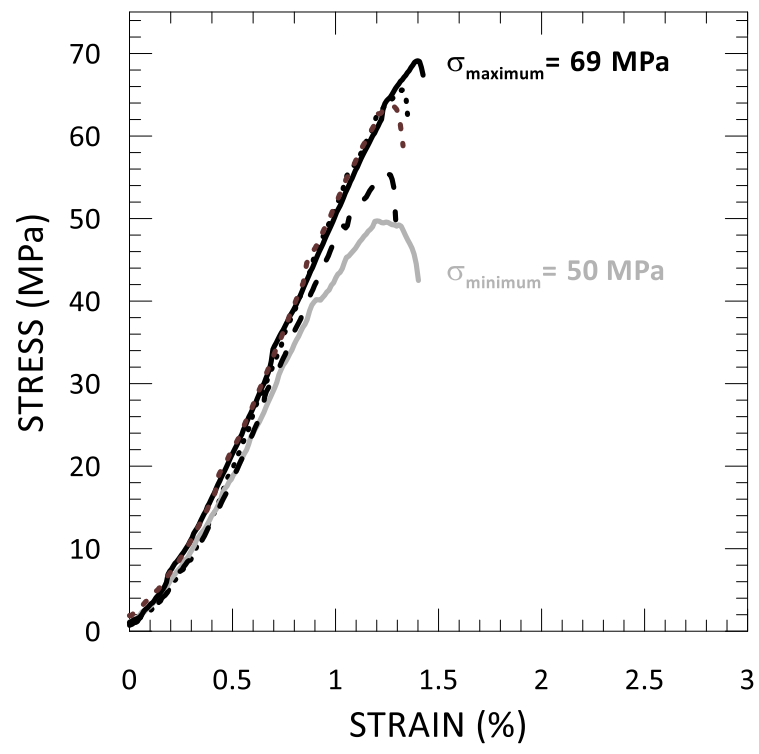

Figure 5. Stress vs strain curves for geopolymeric mortar derived from calcined clay and deformed in air at room temperature.

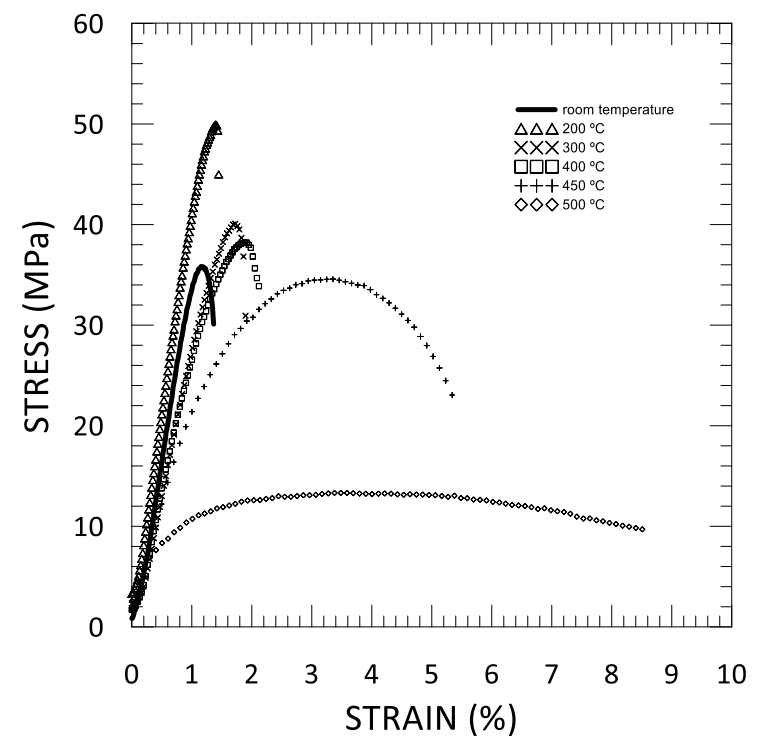

Figura 6. Stress vs strain curves for geopolymeric mortar derived from ignimbrite powder and deformed in air at room temperature, $200{ }^{\circ} \mathrm{C} .300{ }^{\circ} \mathrm{C}, 400{ }^{\circ} \mathrm{C}, 450{ }^{\circ} \mathrm{C}$ and $500{ }^{\circ} \mathrm{C}$.

Figure 6 shows stress vs. strain curves obtained at test temperatures from room temperature to $500^{\circ} \mathrm{C}$ in air for samples of geopolymeric mortar derived from ignimbrite powder. The results reveal an increase in maximum resistance with a test temperature up to $200^{\circ} \mathrm{C}$. From test temperatures of $200^{\circ} \mathrm{C}$ onwards a progressive reduction of the maximum resistance values occurs, accompanied by a transition from totally fragile to semi-ductile behavior.

At a test temperature of $450^{\circ} \mathrm{C}$ a semi-ductile behavior is noticed, with deformation of the sample of up to $5 \%$ without catastrophic failure, unlike the sample tested at $300^{\circ} \mathrm{C}$, where the fault is clearly fragile with deformation of $1.8 \%$ before catastrophic failure. 
At a test temperature of $500^{\circ} \mathrm{C}$, the sample shows a semi-ductile behavior with a deformation of up to $9 \%$ without fracture.

From the curves of Figure 6 and considering the typical microstructure of the materials studied in this research, it is suggested that the fragile-semi-ductile transition is due to the softening of the geopolymeric binder phase, which allows the movement of individual particles of fine sand in the continuous softened phase. This possible deformation mechanism is sensitive (accelerates) to the increase in temperature, as shown in Figure 6.

\section{Conclusions}

Geopolymeric mortars derived from demolition waste have been successfully fabricated by mixing solid materials, adding 12 molar sodium hydroxide solution, and hardening at room temperature.

The typical microstructure of the geopolymeric mortars studied consists of a discontinuous phase of fine sand embedded in a continuous one of geopolymeric binder.

The increase in temperature from room temperature to $200^{\circ} \mathrm{C}$ produces an increase in the maximum resistance values.

Test temperatures greater than $200^{\circ} \mathrm{C}$ produce a progressive decrease in mechanical resistance, which is accompanied by a fragile-semi-ductile transition.

The mechanism of deformation suggested to explain the fragile-semi-ductile transition noticed in the materials studied is the softening of the geopolymeric binder phase with the increase in temperatures.

\section{Acknowledgements}

This work was supported by the project no. 106-2017FONDECYT.

Consejo Nacional de Ciencia, Tecnología e Innovación Tecnológica and Servicio Nacional de Capacitación para la Industria de la Construcción, Peru.

\section{References}

1. S. Ahmari, X. Ren, V. Toufigh, L. Zhang. Constr Build Master; 35: 718-729 (2012).

2. H. Choi, M. Lim, H. Choi, R. Kitagaki, T. Noguchi. J Environ Prot; 5: 583-596 (2014).

3. D. McKelvey, V. Sivakumar, A. Bell, G. McLaverty.; 6(2): 59-68 (2002).

4. P. Duxson, A. Fernandez-Jimenez, J.L. Provis, G.C. Lukey, A. Palomo, J.S.J. van Deventer ;42(9):29172933 (2007).

5. D.R. Hack, D.P. Bryan. 7th Edition, Littleton, Colorado, Society for Mining, Metallurgy and Exploration; p. 1105-1119 (2006).

6. J.M. Khatib. (UK): Woodhead Publishing Limited (2009).

7. A. Arulrajah, J. Piratheepan, M.M. Disfani, M.W. Bo. J Mater Civ Eng; 25(8): 1077-1088 (2013).

8. F. Tomosawa, T. Noguchi. In: Sakai K, editor. Integrated design and environmental issues in concrete technology. E \& FN Spon, London, UK. p. 263-372 (1996).

9. J.R. Costes, C. Majcherczyk, I.P. Binkhorst. Total Recycling of Concrete 2007; http://omogine.blogspot.com/.

10. Z. Aygun and M. Aygun. Spectrochimica Acta Part A: Molecular and Biomolecular spectrocopy. ELSEVIER. Vol, 166:73 - 78 (2016). 